\title{
A RELEVÂNCIA DAS INTERVENÇÕES PSICOPEDAGÓGICAS NO PROCESSO DE ALFABETIZAÇÃO E LETRAMENTO DE ESTUDANTES COM TRANSTORNO DO DÉFICIT DE ATENÇÃO E HIPERATIVIDADE
}

\author{
THE RELEVANCE OF PSYCHOPEDAGOGIC INTERVENTIONS IN THE LITERACY AND \\ LITERACY PROCESS OF STUDENTS WITH ATTENTION DEFICIT AND \\ HYPERACTIVITY DISORDER
}

Cristina Silveira Darin ${ }^{1}$

RESUMO: O Transtorno de Déficit de Atenção e Hiperatividade (TDAH) é atualmente um dos temas mais polêmicos e controversos envolvendo crianças em idade escolar, que divide estudos e pesquisadores. Devido à inadequação ao padrão pedagógico convencional, é comum que alunos com TDAH apresentem comportamentos inadequados ao mesmo tempo em que são percebidos, por parte dos docentes, como "entraves" a manutenção de um clima harmonioso em sala de aula. Diante do mencionado observa-se que na atualidade, muito se discute sobre a questão do aluno com TDAH, mas em contrapartida são poucos os profissionais da área da educação que conhecem e compreendem as dificuldades enfrentadas por estes alunos relacionadas à atenção, hiperatividade e impulsividade. Diante do exposto, o estudo tem como objetivo geral dentificar o papel da intervenção psicopedagógica no tratamento de crianças com TDAH em idade de alfabetização, perpassando por uma revisão de literatura onde será definido o TDAH, assim como abordaremos aspectos relacionados a identificação das causas e implicações no processo de escolarização e por fim contextualizaremos a alfabetização e letramento, destacando possíveis intervenções psicopedagógicas que possam auxiliar no processo de alfabetização de estudantes com TDHA.

Palavras-chave: Transtorno do Déficit de Atenção e Hiperatividade. Psicopedagia.

ABSTRACT: Attention Deficit Hyperactivity Disorder (ADHD) is currently one of the most controversial and controversial topics involving school-age children, which divides studies and researchers. Due to the inadequacy of the conventional pedagogical pattern, it is common for students with ADHD to present inappropriate behaviors while they are perceived by teachers as "obstacles" to maintaining a harmonious climate in the classroom. In view of the aforementioned, it is observed that today, much is discussed about the issue of the student with ADHD, but on the other hand, few professionals in the area of education know and understand the difficulties faced by these students related to attention, hyperactivity and impulsivity. Given the above, the study has as general objective to identify the role of psychopedagogical intervention in the treatment of children with ADHD at literacy age, going through a literature review where ADHD will be defined, as well as aspects related to the identification of causes and implications in the schooling process and finally we will contextualize literacy and literacy, highlighting possible psychopedagogical interventions that can help in the literacy process of students with ADHD.

Keywords: Attention Deficit Hyperactivity Disorder. Psychopedagogy.

${ }^{\text {I }}$ Graduação: Pedagogia. Pós graduação: Psicopedagogia e gestão escolar. 


\section{INTRODUÇÃO}

O Transtorno de Déficit de Atenção e Hiperatividade (TDAH) é atualmente um dos temas mais polêmicos e controversos envolvendo crianças em idade escolar, que divide estudos e pesquisadores. O TDAH foi descrito pela primeira vez em 1902 pelo pediatra inglês George Still, o qual notou mudanças consideráveis de comportamento em crianças. O mesmo considerava que o fator não era imputado por problemas educacionais, mas sim por determinantes biológicos. $O$ transtorno vem sendo estudado em vários países e desde i96o recebeu diversas denominações, tais como: irrequietação Phillis; doença de Still; distúrbio de Impulso; lesão Mínima do Cérebro; disfunção Cerebral Mínima e Reação Hipercinética da Infância.

Em meados de 1980, o Manual Diagnóstico e Estatístico dos Distúrbios Mentais (DSM-III) denominou o transtorno como TDHA, pelo fato de considerarem que a dificuldade em se concentrar e manter a atenção era o fator predominante. No entanto, em 1987, o Transtorno de Déficit de Atenção foi renomeado para TDAH, recuperando o destaque na hiperatividade e na impulsividade, sintomas que outrora haviam sido menos considerados. 374 Após a publicação do Manual Diagnóstico e Estatístico dos Distúrbios Mentais (DSM-IV), reconhece-se a existência do TDAH do tipo com predominância na desatenção.

Autores pesquisadores como Barkley (2002) pressupõe o TDAH como um dos distúrbios de comportamento que atinge a vida do indivíduo tanto sócio afetiva, como profissional e, principalmente, escolar e, com isso, ele pode ser caracterizado por atividade motora excessiva, falta de atenção, impulsividade. Acredita-se que seja uma das principais fontes de encaminhamento de crianças escolares ao sistema de saúde por parte dos profissionais da educação. Somando uma diversidade de queixas escolares, muitos educadores ao se referirem a tais alunos, os consideram como "corpos que não param”.

Devido à inadequação ao padrão pedagógico convencional, é comum que alunos com TDAH apresentem comportamentos inadequados ao mesmo tempo em que são percebidos, por parte dos docentes, como "entraves" a manutenção de um clima harmonioso em sala de aula. Diante do mencionado observa-se que na atualidade, muito se discute sobre a questão do aluno com TDAH, mas em contrapartida são poucos os profissionais da área da educação que 
conhecem e compreendem as dificuldades enfrentadas por estes alunos relacionadas à atenção, hiperatividade e impulsividade.

A relevância de se dissertar sobre essa temática tem sido uma atividade desafiadora, seja por incidência da problemática; pelo ceticismo da existência do transtorno; ou até mesmo pela tendência de a literatura que versa sobre o assunto condenar alguém. Diante deste desafio, os argumentos vão desde a afirmação de que a escola não oportuniza condições positivas de aprendizagem para os alunos com TDAH, pois os conteúdos não são atraentes e significativos e os professores não conseguem propor uma metodologia diferenciada que atraia a atenção do aluno com TDAH; até o pretexto de que a causa seja exclusivamente biológica, ou ainda, seja a ausência da imposição de limites e regras pelos genitores.

É importante salientar que ao se observar os comportamentos característicos do TDHA em um estudante e o principal, considerando que essas condutas causam impactos negativos no processo de e alfabetização e letramento da criança da criança, a família deve ser comunicada acerca da suspeita e o mesmo deverá ser encaminhado a uma equipe multidisciplinar a qual será responsável pelo seu diagnóstico, tratamento e intervenções sendo esta composta por médicos, psicólogos e especialmente por um psicopedagogo, considerando que compete a este profissional investigar as principais dificuldades de aprendizagem apresentadas, os fatores cognitivos e emocionais comprometidos, bem como o desempenho escolar é afetado pelos sintomas do transtorno. Considerando tais pressupostos este estudo busca coletar dados e informações no sentido de responder ao seguinte questionamento: qual a relevância da atuação do psicopedagogo para a alfabetização e letramento de estudantes com Transtorno de Déficit de Atenção e Hiperatividade?

Dado o exposto, delimitou-se o seguinte objetivo geral com o intuito de responder ao problema da pesquisa: identificar o papel da intervenção psicopedagógica no tratamento de crianças com TDAH em idade de alfabetização, sendo este fragmentando originando os seguintes objetivos específicos: (a) definir o TDAH, identificando as causas e implicações no processo de escolarização; (b) contextualizar alfabetização e letramento; (c) apresentar intervenções psicopedagógicas que possam auxiliar no processo de alfabetização de estudantes com TDHA. 
Vale destacar que o transtorno tem sido um dos maiores motivos que levam crianças consideradas "difíceis e problemáticas" aos consultórios médicos e deste modo os especialistas da medicina em grande maioria defendem a medicalização como forma de "docilizar" estes corpos na intenção de lhes oferecer melhor qualidade de vida. Contudo, diversas são as divergências acerca deste tipo de tratamento, pois alguns pesquisadores da área apontam que esta perspectiva transforma estes sujeitos em meros "robôs". Em contrapartida, outros pesquisadores apostam que o uso de medicamentos para controle dos sintomas do TDHA é extremamente relevante e deste modo, necessário. Deste modo, a pesquisa justifica-se a presente pela necessidade de aprofundamento dos estudos acerca do Transtorno de Déficit de Atenção e Hiperatividade, tornando-se essencial para que novos direcionamentos sejam viabilizados no processo ensino e aprendizagem.

Este estudo foi propiciado por meio de uma pesquisa bibliográfica, cujo benefício se dá pelo fato de que esta possibilita investigar as diferentes contribuições cientificas sobre o tema abordado permitindo ao pesquisador utilizar as informações coletadas para enriquecimento de suas proposições. Com tal intuito procedeu-se a busca de publicações que abordaram questões

relacionadas ao tema, sendo estas posteriormente analisadas e interpretadas para servirem como aporte teórico na construção da fundamentação da pesquisa.

\section{DESVENDANDO O TRANSTORNO DO DÉFICIT DE ATENÇÃO E HIPERATIVIDADE}

O TDAH é um transtorno de desenvolvimento do autocontrole que consiste em disfunções com os períodos de atenção, com contenção do impulso e com o nível de atividade (BARKLEI, 2002). Insta esclarecer que tais sintomas não são controlados pela criança, e observou-se a mesma não apresenta a predisposição de capacidade de monitorar seus próprios comportamentos por um determinado período de tempo. Outrossim, não é consequência de ausência de disciplina ou controle por parte dos genitores: "O TDAH é um transtorno real, um problema real, e frequentemente, um obstáculo real" (BARKLEY, 2002, p. 35).

Simultaneamente, estudos apontam que existem ainda dois problemas associados a este transtorno que são: resistência para seguir regras e instruções e a incompatibilidade em 
suas respostas a determinadas situações. Esses sintomas irão causar sérios impactos na vida escolar do sujeito com TDHA; em seus relacionamentos familiares e amorosos; sua vida social e a vida laboral também poderão ser prejudicadas (IBIDEM).

Vale revelar que, dados apresentados pela Associação Brasileira do Déficit de Atenção, demonstram que o TDAH acomete em torno de 3 a $5 \%$ da população infantil do Brasil e de vários países do mundo onde o transtorno já foi pesquisado. Nos adultos estima-se um percentual de aproximadamente 4\%. Segundo o DSM-5, levantamentos populacionais apontam que o TDAH ocorre na maioria das culturas em cerca de $5 \%$ das crianças e $2,5 \%$ dos adultos (IBIDEM).

Em 1902, George Still, pediatra inglês, descreveu o Transtorno de Déficit de Atenção e Hiperatividade como TDAH, relacionando-o a dois casos clínicos infantis por ele diagnosticado, como alterações de comportamento e hiperatividade. Buscando explicar o transtorno ora detectado, o pediatra baseou-se nas adversidades cerebrais, ambientais e escolares (SILVA; CABRAL, 2015).

O Transtorno do Déficit de Atenção e Hiperatividade (TDAH) é um transtorno psiquiátrico prevalente e persistente que surge precocemente na infância, com uma taxa atual de prevalência de $5 \%$ em crianças de quatro a 17 anos de idade. O distúrbio é classicamente caracterizado por sintomas de desatenção, impulsividade e hiperatividade (GONÇALVES, 2008).

Acredita-se que o TDAH tenha início geralmente na primeira infância, embora o diagnóstico seja tipicamente determinado na idade escolar. O distúrbio é particularmente relevante na sociedade atual, pois é um dos diagnósticos mais comuns em contextos educacionais e considerado um dos problemas mais frequentes de saúde mental infantil. Além disso, inúmeras crianças diagnosticadas com o transtorno passam a ter problemas relacionados à educação, funcionamento social e/ou outras doenças mentais. Dado o exposto, o transtorno pode ser tido como um dos altos custos individuais e sociais para a população (LACET; ROSA, 2017).

Contudo, pesquisadores como Mattos (2007), defendem que os sintomas do TDAH podem surgir logo nos primeiros anos de vida, pois foram observadas alterações no 
desenvolvimento neurológico e emocional do indivíduo, e que ainda alguns estudos revelaram que as mães de crianças portadoras do transtorno, afirma que elas costumavam se movimentar de forma demasiada, quando ainda em seus ventres e ao nascerem nos primeiros meses demonstram ser irritadas, choronas, irrequietas durante o sono.

Registre-se que, segundo o DSM-5 (Manual Diagnóstico e Estatístico de Transtornos Mentais), o TDAH é mais recorrente no sexo masculino do que no feminino na população geral, na proporção de 2:I em crianças e de I,6: I em adultos, com maiores chances de pessoas do sexo feminino se apresentarem primariamente com características de desatenção em comparação com as do sexo masculino (BARKLEI, 2002).

Torna-se oportuno especular, se efetivamente o TDAH é uma condição psiquiátrica de início histórico recente e que sua incidência pode ter sido muito relativamente rara nos tempos antigos (como anorexia) ou, um distúrbio que esteja em nossa espécie por vários milhares de anos (como a esquizofrenia). Preencher essa lacuna no conhecimento histórico, colocaria restrições úteis nas teorias sobre o que causa o TDAH (PETERS, 2012), contribuindo inclusive para a concepção de novos tratamentos e quiçá, pesquisas para desenvolvimento de medicamentos.

Cumpre esclarecer, que não existe uma descrição óbvia do TDAH na literatura antiga, apesar dos distintos tipos de personalidade descritos por Galeno, proeminente médico e filósofo romano. A história moderna apresenta uma descrição médica semelhante ao TDAH a mais de 200 anos. Descrições análogas a TDAH ou TDAH sem hiperatividade são encontradas esporadicamente na literatura europeia do final do século XVIII ao início do século XX, e nos Estados Unidos a partir do início do século XIX (NIGG; BARKLEY, 20I2).

Na década de 1970, inspirados pelo progresso da psicologia cognitiva e experimental na definição operacional da atenção, pesquisadores enfatizaram problemas com atenção sustentada e controle de impulsos, além da hiperatividade. O modelo de Douglas, que foi bastante influente e também destacou uma tendência a buscar o reforço imediato, contribuiu para o rebatismo do transtorno, como distúrbio de déficit de atenção (DDA) em I980. (WAGNER et al., 2016). 
Naquela época, a síndrome foi redefinida em termos mais restritos do que o que havia sido anteriormente o DDA, e o termo DDA foi abandonado. Em 1987, o distúrbio foi renomeado para "transtorno do déficit de atenção e hiperatividade" no DSM-V, e uma lista única de itens incorporando os três sintomas (hiperatividade, falta de atenção, impulsividade) foi especificado que tinha melhor validade estatística (IBIDEM).

O denominado Transtorno de Déficit de Atenção e Hiperatividade (TDAH) tem paulatinamente ocupado lugar de destaque ao consideramos a prevalência dos quadros psicopatológicos da infância e adolescência na atualidade. Nas últimas décadas, foram realizadas inúmeras investigações cientificas que tomam como objeto a prevalência do TDAH. As crianças, adolescentes e adultos com o transtorno estão sujeitos a apresentar problemas na esfera social, interpessoal e intrapessoal, tais como: baixa autoestima, conflitos familiares, problemas de relacionamento entre iguais e conjugais, maior probabilidade de envolvimento em acidentes automobilísticos, práticas sexuais de risco, uso de substâncias ilícitas, comportamentos antissociais, entre outros (HORA et al., 2015).

Quando diagnosticada pelos critérios do Manual Diagnóstico e Estatístico de Transtornos Mentais V (DSM-V), a doença afeta entre 5 e 7\% das crianças. Quando diagnosticada pelos critérios da CID-ro afeta entre r e 2\%. Estima-se que em 2015 o transtorno já afetasse cerca de 5,I milhões de pessoas. A prevalência é muito semelhante entre países. As aparentes diferenças de valores são resultado de diferentes critérios de diagnóstico usados em cada país (DSM-V, 2013).

Conforme aponta a Associação Brasileira do Déficit de Atenção - ABDA (2017):

Estudos científicos demonstraram que portadores de TDAH têm alterações na região frontal e as suas conexões com o resto do cérebro. A região frontal orbital é uma das mais avançadas no ser humano em comparação com outras espécies animais e é encarregada pela repressão do comportamento (isto é, controlar ou interditar comportamentos inconvenientes), pela competência de manter a atenção, memorizar, autocontrolar, organizar e planejar. $\mathrm{O}$ que aparenta estar desordenado nesta região cerebral é o desempenho de um sistema de substâncias químicas chamadas neurotransmissoras (principalmente dopamina e noradrenalina), que transmitem informações entre as células nervosas (neurônios) (ABDA, 2017).

O TDHA é marcado por uma série de sinais e sintomas que foram estudados a partir de diversas áreas tais como a psicologia, a psicopedagogia, a medicina entre outras. A partir do 
modelo médico neurológico, o TDAH é compreendido como possíveis disfunções ou anomalias cerebrais. Para a psicopedagogia, a hiperatividade infantil encontra-se associada a deficiências perceptivas e dificuldades de aprendizagem. $O$ modelo psiquiátrico a compreende com uma excessiva atividade motora, ausência de atenção e impulsividade. (BONADIO; MORI, 2013).

Para um diagnóstico acertado do TDH, torna-se necessário que se observem alguns parâmetros, através da observação dos sintomas clínicos: desatenção, a hiperatividade e a impulsividade que a criança ou o adolescente apresentam no percurso de seu desenvolvimento, e que comprometam suas rotinas e relações pessoais e interpessoais na escola, no trabalho e no lar. Bonadio e Mori (I, 2013, p. 45-46) complementam esta concepção, esclarecendo que:

Os critérios utilizados para a realização do diagnóstico podem ser encontrados no DSM, utilizado com frequência nos Estados Unidos ou no CID ro, ambos usados também no Brasil por médicos e psicólogos ao emitir diagnósticos. O DSM elenca uma série de características a ser identificada para emitir o diagnóstico de TDAH, cuja essência se configura na persistência de desatenção e/ou hiperatividade em graus desproporcionais comparados a pessoas com desenvolvimento equivalente, Sintomas hiperativo-impulsivos motivadores de prejuízo devem se manifestar antes dos sete 380 anos. Os sintomas devem estar presentes em pelo menos dois contextos (na escola, no trabalho ou em casa) e devem interferir de maneira significativa no funcionamento social, acadêmico ou ocupacional da pessoa, considerado apropriado ao nível de desenvolvimento

De acordo com o manual DSM-IV (Diagnostic and Statistical Manual, $4^{\text {a }}$ edição) o TDAH se caracteriza por uma combinação de dois grupos de sintomas: I) desatenção; 2) hiperatividade e impulsividade. Esses sintomas são relacionados no DSM-IV para tornar o diagnóstico mais normatizado e se caracteriza da seguinte forma:

Sintomas da desatenção (devem ocorrer frequentemente): Prestar pouca atenção a detalhes e comete erros por falta de atenção; Dificuldade de se concentrar tanto nas tarefas escolares quanto em jogos e brincadeiras; Numa conversa, parece prestar atenção em outras coisas e não escutar quando lhe dirigem a palavra; Dificuldade em seguir instruções até o fim ou deixar tarefas e deveres sem terminar; Dificuldade de se organizar para fazer algo ou planejar com antecedência; Evita antipatiza ou reluta a envolver-se em tarefas que exijam esforço mental constante (como tarefas escolares ou deveres de casa); Perda de objetos necessários para a realização de tarefas ou atividades do dia-a-dia. Distrai-se com muita facilidade com coisas à sua volta ou mesmo com os próprios pensamentos. Daí que surgem as expressões que muitos pais e professores usam quando percebem sua distração: "Parecem que vivem no mundo da lua" ou que "sonham acordados". Esquecem coisas que deveriam fazem no dia-a- 
dia. Sintoma de hiperatividade e impulsividade (devem ocorrer frequentemente): Ficar mexendo as mãos e pés quando sentados ou se mexer muito na cadeira; Dificuldade de permanecer sentado em situações em que isso é esperado (sala de aula, mesa de jantar, etc.); Correr ou escalar coisas, em situações nas quais isto é inapropriado (em adolescentes e adultos pode se restringir a um sentir-se inquieto por dentro); Dificuldades para se manter em atividades de lazer (jogos e brincadeiras) em silêncio; Parecer ser "elétrico" e a "mil por hora"; Falar demais; Responder a perguntas antes de elas serem concluídas. É comum responder à pergunta sem ler até o final; Não conseguir aguardar a sua vez (nos jogos, na sala de aula, em filas, etc.); Interromper os outros ou se meter nas conversas alheias (DSM - IV, 1995).

Em conformidade com a classificação atual do Manual Diagnóstico e Estatístico de Transtornos Mentais, existem três tipos de principais de TDHA: tipo desatento; tipo hiperativo-impulsivo; tipo misto. Cada tipo será descrito na tabela I:

Tabela r: Tipos de TDHA

\begin{tabular}{cl}
\hline Tipo & \multicolumn{1}{c}{ Descrição } \\
\hline TDHA Tipo & As características mais habituais do TDAH Tipo Desatento são: a desatenção, persistência à \\
Desatento & $\begin{array}{l}\text { distração; dificuldade em manter o foco na realização de atividades mais complexas e } \\
\text { percepção da passagem do tempo. }\end{array}$
\end{tabular}

TDHA Tipo Hiperativo Impulsivo

TDHA Misto ou Combinado
A agitação, hiperatividade, impulsividade são os traços mais significativos. Nesse caso a hiperatividade pode ser uma complicação, tendo em vista que desestabiliza o ambiente a seu redor. A procura constante por estimulação, impulsividade e dificuldade em refletir antes de;81 agir pode ocasionar consequências, tanto para crianças quanto para adultos.

Este tipo demonstra concomitantemente as características dos tipos de TDAH desatento e hiperativo-impulsivo. Mesmo nos tipos mistos, a manifestação integral sofre uma variação de acordo. Em crianças menores, a hiperatividade é mais explícita, isto se deve por não ser conveniente aguardar um grau elevado de "concentração". Com o início da alfabetização, passa a ser mais perceptível que, além da agitação, pode ocorrer também uma tendência à distração, esquecimentos e desorganização. De um modo geral, a hiperatividade é mais frequente na infância e comumente diminui com o decorrer dos anos. Em adultos, normalmente se manifesta como hiperatividade mental.

Fonte: Elaborado pela autora baseado em DSM - IV (1995).

Diante da gravidade do transtorno, convém destacar que os estudos de prevalência são imprescindíveis no monitoramento da frequência do TDAH na população, e na identificação dos fatores de risco e consequências na saúde pública. Tais estudos auxiliam na melhoria da qualidade de vida do indivíduo por identificar medidas preventivas e possíveis formas de controle. 


\section{O SUJEITO COM TDHA E SUA INSERÇÃO NO CONTEXTO ESCOLAR}

A inserção de uma criança com TDHA no contexto escolar não é uma tarefa simples, considerando que conforme esclarece Rohde e Benczik (I999, pág. 88):

Atualmente, o Transtorno de Déficit de Atenção/Hiperatividade (TDAH) constitui uma complexa desordem comportamental que leva a criança a graus variáveis de comprometimento na vida social, emocional, escolar e familiar. Esse transtorno caracteriza-se por distúrbios motores, perceptivos, cognitivos e comportamentais, expressando dificuldades globais do desenvolvimento infantil.

Estes sintomas são extremamente complexos e causam impactos consideráveis no processo de ensino e aprendizagem do aluno portador do transtorno. Contudo, pesquisas apontam que no contexto escolar, docentes e equipe pedagógica, assumem erroneamente a função de especialistas e, ao não compreenderem o comportamento de determinados alunos, lançam mão de pontos de vista, por vezes equivocados, que remetem para um diagnóstico errôneo por parte dos mesmos, e assim atestam diagnósticos, principalmente de Transtorno de Déficit de Atenção e Hiperatividade (TDAH), encaminhando estes alunos para avaliações psiquiátricas, neurológicas e/ou psicológicas. Outro fator que merece ser destacado está no

fato de que o aluno com TDHA apresenta comportamentos considerados “indesejáveis" e 382 assim, questiona-se se a medicalização não seria a melhor saída para o tratamento do transtorno (GUARIDO, 2008).

Tais aspectos reforçam a premissa de que ao ser inserido no contexto escolar o aluno com TDHA irá enfrentar inúmeros obstáculos. Os mitos e inverdades que cerceiam este transtorno nos mostram a emergência de pesquisas acerca da patologia e quais os malefícios que rotulações podem ocasionar a este público.

Baseado nessas concepções pode-se supor que compete ao docente que venha a atuar junto a um aluno com TDHA que este tenha conhecimentos sólidos acerca do transtorno, o que vem a ser uma variável significativa e que, por conseguinte, facilitará a inserção deste estudante no ambiente escolar, pois deste modo o profissional compreenderá as nuances que envolvem o processo de interação e desenvolvimento do aluno, considerando que o aluno com TDHA apresenta diversas especificidades, inclusive relacionadas ao seu comportamento, e isso exige habilidades e competências para atuar proativamente. Compete ao profissional da 
educação que se proponha a trabalhar na perspectiva de inclusão no atendimento do aluno com TDHA compreender que:

A presença dos sintomas de TDAH pode ocasionar repercussão na vida escolar dos indivíduos acometidos. A falta de atenção ou a hiperatividade/impulsividade podem gerar condutas inapropriadas, nem sempre favoráveis para que se possa reter, coordenar, assimilar e acomodar a informação necessária para o aprendizado pleno. $\mathrm{O}$ correto diagnóstico e tratamento poderão reduzir o impacto da doença na vida do indivíduo e possibilitar melhor inserção social e satisfação pessoal na vida adulta. Esses resultados são ampliados dentro do ambiente escolar, na sua relação com o processo de aprendizagem, assim como na forma que olhamos para essa criança e compreendemos sua ação corporal dentro de sala de aula. (OLIVEIRA, 2015, p. 7).

Diversos são os aspectos a serem observados para que ocorra uma inserção efetiva do indivíduo com TDHA no contexto escolar, contudo, e de suma importância que ocasionalmente sejam apresentadas e discutidas soluções e estratégias de apoio para promoção à aprendizagem das crianças diagnosticadas com TDAH é possível, necessária e aplicável por todos os envolvidos - escola, família e sujeito, sendo a eles propiciados intervenções e tratamentos que venham a contribuir para que estes tenham uma melhor qualidade de vida, obviamente perpassando pela alfabetização e letramento destes sujeitos, conceitos que serão abordados na sequência.

\section{CONTEXTUALIZANDO ALFABETIZAÇÃO E LETRAMENTO}

É de consenso geral que alfabetização e letramento são processos educacionais que levam ao acesso à língua escrita com a decodificação da mesma, ou seja, a leitura. Entretanto, algumas considerações devem ser feitas para que possamos entender a diferença, ainda que sutil, entre ambos. Sutil porque, sem um olhar atento, podemos ver ambos os processos como aprendizagem do aprender a ler e escrever, porém, se observarmos com mais profundidade, perceberemos que, embora, ambos estejam dentro de um sistema complexo (do latim complexus = tecido junto) o que significa dizer que alfabetização e letramento são indivisíveis pois, ambos levam ao aprendizado da leitura e da escrita, porém, por caminhos diferentes e resultados diferentes. Este é o grande ponto a se compreender (PETRONILO, 2007).

Enquanto a alfabetização apenas apresenta à criança a língua oral traduzida em códigos desenhados (escrita), o letramento insere o conceito de que não basta saber apenas decodificar, ou seja, saber ler e saber escrever, faz -se necessário empregar a leitura e a escrita no dia a dia, 
faz com que a leitura e a escrita tenham um sentido mais amplo qual seja, aperfeiçoe a prática comunicativa, que seja um processo em que as interações verbais sejam feitas dentro e fora da escola. Deve haver um sentido maior no uso da língua falada e escrita.

Assim, tem-se a aprendizagem da leitura e da escrita como um processo dinâmico, no entanto, este processo tem dois acessos: uma técnica (alfabetização) e outra que diz respeito ao uso social (letramento). Deste modo, subtende-se que ambos os processos estão imbricados, o que significa dizer que o processo de alfabetização é desencadeado com o acesso à cultura escrita, o letramento. Caso não ocorra este acesso à cultura escrita e apenas inserido o aprendizado automático de decodificação, teremos como resultado apenas os analfabetos funcionais.

Brotto (2008, p. II) apresenta considerações a respeito da diversidade de práticas que a palavra letramento pode abranger:

Letramento é um termo recente que tem sido utilizado para conceituar e/ou definir variados âmbitos de atuação e formas de participação dos sujeitos em práticas sociais relacionadas de algum modo à leitura e à escrita. Pode se referir a práticas de letramento de crianças em período anterior ao período de escolarização; à aprendizagem escolarizada da leitura e da escrita, inicial ou não; à participação de 384 sujeitos analfabetos ou alfabetizados não escolarizados na cultura letrada, ou, ainda, referir-se à condição de participação de grupos sociais não alfabetizados ou com um nível precário de apropriação da escrita em práticas orais letradas. (BROTTO, 2008, p. II).

Percebe-se que o letramento é anterior ao processo de alfabetização, e que a alfabetização é o desencadeamento do letramento através do acesso à cultura escrita, cujo processo é cultural e social. Observa-se que, na medida em que trabalhamos com letramento, passamos a perceber que não basta saber ler e escrever, é preciso saber utilizar a leitura e a escrita em situações reais, em que façam sentido tanto na comunicação oral quanto escrita, dentro e fora da escola. Em que pese os conceitos de alfabetização e letramento, está na essência de cada um à sua tênue diferença. (BROTTO, 2007).

O letramento traz consigo, a possibilidade de reflexão, de pensamento próprio, de escolha. Está inserido num contexto social que faz com que a decodificação de um código, o alfabeto, seja uma ferramenta que lhes possibilita um novo olhar naquilo que lhe é ensinado e assimilado, não como informação, mas transformado em conhecimento. $O$ conhecimento 
jamais será esquecido, ele se forma como uma teia, que vai se fechando à medida que novas informações são introduzidas, e quanto mais informação, mais ela encontra base em conhecimentos já adquiridos anteriormente.

Como visto, alfabetização e letramento não possuem o mesmo significado, tendo em vista que o reconhecimento da língua escrita é mais uma ferramenta e com ela vamos mais longe, mas devemos lembrar também do conhecimento empírico, dos nossos antepassados, que ouviam, compreendiam e assimilavam informações, transformando-as em conhecimento, seja pela própria vivência ou por ouvir, de histórias contadas. O letramento é cultural, por isso muitas crianças já vão para a escola com o conhecimento alcançado de maneira informal absorvido no cotidiano.

Atualmente, sabe-se da importância da língua escrita, pois é através dela que podemos nos comunicar das mais diferentes formas e deste modo o aluno com TDHA em decorrência das características próprias da síndrome tendem a apresentar dificuldades de aprendizagem, as quais impedem a efetividade de seu processo de alfabetização de letramento.

Em síntese, cumpre esclarecer que o processo de aprendizagem se dá no sistema nervoso central e ele é influenciado por vários fatores. A dificuldade de aprendizagem, ocorre quando um discente não consegue assimilar novos conceitos através dos mesmos métodos que outros estudantes. Para um melhor entendimento, Grigorenko e Ternemberg, (2003, p. 29) esclarecem que a dificuldade de aprendizagem pode ser compreendida como:

[...] um distúrbio em um ou mais dos processos psicológicos básicos envolvidos no entendimento ou no uso da linguagem, falada ou escrita, que pode se manifestar em uma aptidão imperfeita para ouvir, pensar, falar, ler, escrever, soletrar ou realizar cálculos matemáticos

Para Smityh e Strick, (20oI, p. I4) as dificuldades de aprendizagem são “(..) problemas neurológicos que afetam a capacidade do cérebro para entender, recordar ou comunicar informações”. Vale pontuar que as dificuldades de aprendizagem podem ser ocasionadas por diversos fatores sendo eles: orgânicos, emocionais e ambientai, deste modo a definimos como um fenômeno multifatorial.

Em face à discussão em tela, o docente ao observar que seu aluno apresenta dificuldades de aprendizagem, deve encaminhá-lo para uma avaliação com uma equipe 
multidisciplinar, afim de que se possa chegar a um diagnóstico preciso de modo que lhe seja ofertado o tratamento e intervenções adequadas.

\section{A ATUAÇÃO DO PSICOPEDAGOGO NO PROCESSO DE INCLUSÃO DO ALUNO COM TDAH}

A Psicopedagogia surgiu na Europa em meados do século XIX tendo em vista a inquietação de profissionais da área de Medicina, Psicologia e Psicanálise acerca dos problemas de aprendizagem e seus prováveis ajustamentos. (FAGALI; VALE, 2009). Deste modo, pode-se afirmar que:

A Psicopedagogia tem por objeto de estudo a aprendizagem do ser humano que na sua essência é social, emocional e cognitivo - o ser cognoscente, um sujeito que para aprender pensa, sente e age em uma atmosfera, que ao mesmo tempo é objetiva e subjetiva, individual e coletiva, de sensações e de conhecimentos, de ser e vir a ser, de não saber e de saber. Essa ciência estuda o sujeito na sua singularidade, a partir do seu contexto social e de todas as redes relacionais a que ele consegue pertencer. (PORTILHO, 2003, p. 125).

Dessa forma, pode-se entender que o Psicopedagogo é um profissional destinado a investigar e compreender dificuldades de aprendizagem que alguns alunos apresentam. A formação em Psicopedagogia é voltada para o estudo do comportamento humano e o processo de aprendizagem das crianças e adolescentes. O psicopedagogo exerce suas atividades em diversos contextos, contudo no âmbito escolar atua no sentido de acompanhar o desenvolvimento cognitivo e psicomotor de estudantes com dificuldades de aprendizagem. Complementando essa ideia, Santos (2016, p. 02) menciona que:

O trabalho na instituição escolar apresenta duas naturezas: $O$ primeiro diz respeito a uma psicopedagogia voltada para o grupo de alunos que apresentam dificuldades na escola. O seu objetivo é reintegrar e readaptar o aluno à situação de sala de aula, possibilitando o respeito às necessidades e ritmos. Tendo como meta desenvolver as funções cognitivas integradas ao afetivo, desbloqueando e canalizando o aluno gradualmente para a aprendizagem dos conceitos conforme os objetivos da aprendizagem formal. O segundo tipo de trabalho refere-se à assessoria junto a pedagogos, orientadores e professores. Tem como objetivo trabalhar as questões pertinentes às relações vinculares professor-aluno e redefinir os procedimentos pedagógicos, integrando o afetivo e o cognitivo, através da aprendizagem dos conceitos e as diferentes áreas do conhecimento. (SANTOS, 2016, p. 02).

O Psicopedagogo em sua atuação poderá auxiliar os docentes no sentido de analisar casos de estudantes com TDAH, buscando estabelecer intervenções no sentido de buscar 
soluções para os problemas que a criança enfrenta, desenvolvendo novas estratégias com o intuito de incluir estes estudantes em todas as atividades executadas em sala de aula.

\section{CONSIDERAÇÕES FINAIS}

Este estudo tinha por objetivo geral identificar o papel da intervenção psicopedagógica no tratamento de crianças com TDAH em idade de alfabetização. Para alcançar este objetivo incialmente tornou-se necessário perpassar por algumas pesquisas que permitissem definir o TDAH, identificando as causas e implicações no processo de escolarização; contextualizar alfabetização e letramento e apresentar intervenções psicopedagógicas que possam auxiliar no processo de alfabetização de estudantes com TDHA.

Neste percurso de escrita foi possível perceber que existem diversos mitos e verdades acerca do TDHA, contudo deve-se mergulhar na busca por bases teóricas que permitam compreender as nuances deste transtorno, o qual ainda não possui uma causa específica e cientificamente comprovada e para nós futuros profissionais da área de psicopedagogia é de suma importância incorporar tais conhecimentos ao nosso repertório intelectual.

Importante ressaltar que a presença de uma equipe multidisciplinar deve fazer parte do

acompanhamento do paciente com Déficit de Atenção e Hiperatividade para que seja propiciada uma avaliação completa e detalhada do indivíduo a partir de um vasto leque de fatores, tais como: biológicos, psicológicos e educacionais, deste modo, a presença do psicopedagogo é fundamental nessa equipe.

Diante do que foi exposto nesse trabalho, foi possível perceber que a Psicopedagogia é uma área destinada ao aprimoramento do pedagogo, com o intuito de que este possa desenvolver novas metodologias e estratégias para que seu aluno com TDHA possa ter êxito em seu processo de alfabetização e letramento.

\section{REFERÊNCIAS BIBLIOGRÁFICAS}

ASSOCIAÇÃO BRASILEIRA DE DÉFICT DE ATENÇÃO. Perguntas mais frequentes e suas respostas. 2017. Disponível em: http://www.tdah.org.br/sobre-tdah/tdah-perguntasmais-frequeentes-e-suas-respostas.html. Acesso em 03 fev. 202I. 
BARKLEY, Russel A. et al (Org.). Transtorno de déficit de atenção/hiperatividade: manual para diagnóstico e tratamento.3. ed. Porto Alegre: Artmed, 2008.

BONADIO, R. A. A.; MORI.N, N.R. Transtorno de Déficit de Atenção/Hiperatividade: Diagnóstico e Prática Pedagógica. Maringá: Eduem, 2013, 252p.

BROTTO, Ivete Janice de Oliveira. Alfabetização: um tema, muitos sentidos. 2008. $238 \mathrm{f}$. Tese (Doutorado em Educação) - Programa de Pós Graduação em Educação, Universidade Federal do Paraná, Paraná. Disponível em: http://www.ppge.ufpr.br/teses/Do8_brotto.pdf. Acesso em: 07 fev. 2022.

CARVALHO, Joari. Psicologia Social e Educomunicação: questões sobre o processo grupal. Maestría. Instituto de Psicologia da USP, 2009.

DSM-IV. Manual Diagnóstico e Estatístico de Transtornos Mentais. Porto Alegre: Artes Médicas, 1995 .

DSM-IV. Manual Diagnóstico e Estatístico de Transtornos Mentais. Porto Alegre: Artes Médicas, 2013.

GONÇALVES, F.J. Desordem por Déficit de Atenção com Hiperactividade: a escola e a TDAH. 2008. Disponível em: http://ddah.planetaclix.pt/ddah_escola.htm. Acesso em: 04 fev. 2022.

GUARIDO, R. L. O que não tem remédio, remediado está: Medicalização da vida e algumas implicações da presença do saber médico na educação. São Paulo, SP. 2008.

HORA, A.F; SILVA, S; RAMOS, M.P.S; NOBRE, J.P. (2015). A prevalência do Transtorno do Déficit de Atenção e Hiperatividade (TDAH): uma revisão de literatura. Psicologia, volume 29, número 2, p. 47-62, 2015.

LACET, C; ROSA, M.D. (2017). Diagnóstico de Transtorno de Déficit de Atenção e Hiperatividade (TDAH) e sua história no discurso social: desdobramentos subjetivos e éticos. Psic. Rev. São Paulo, volume 26, n.2, 231-253, 2017.

LAKATOS EM.; MARCONI MA. Fundamentos da metodologia científica. 4.ed. São Paulo: Atlas, 20or.

MATTOS, Paulo. No mundo da lua: perguntas e respostas sobre transtorno do déficit de atenção com hiperatividade em crianças, adolescentes e adultos. São Paulo: Lemos Editorial, 2003.

NIGG, J.T; BARKLEY, R.A. Transtorno do déficit de atenção e hiperatividade. In: Mash E, Barkley RA, editores. Psicopatologia do desenvolvimento. Guilford Press; Nova York: no prelo., 2012. 
OLIVEIRA, Carolina Alvim Scarabucci de. O corpo e a criança com TDAH: definições, propostas e desafios. 2015. Disponível em: http://www.eventos.ufu.br/sites/eventos.ufu.br/files/o_corpo_e_a_crianca_com_tdah.pdf. Acesso em: io fev. 2022.

PETRONILO, Ana Paula da Silva. Dificuldade de aprendizagem na leitura e na escrita. Dissertação de Mestrado. Universidade de Brasília, 2007. Disponível em: http://www.ufrgs.br/uploads/138203/Monografia_Ana_Paula_da_Silva_Petrolino.pdf. Acesso em: 07 fev.2022.

ROHDE, L. A. P.; BENCZIK, E. P. Transtorno de déficit de atenção/hiperatividade: o que é? Como ajudar? Porto Alegre: Artmed, I999.

SILVA, K.B.C; CABRAL, S.B. Transtorno do Déficit de Atenção com Hiperatividade. São Paulo: ABDA, 2015.

WAGNER, F; ROHDE, L.A; TRENTINI, C.M. (20I6). Neuropsicologia do Transtorno de Déficit de Atenção/Hiperatividade: Modelos Neuropsicológicos e Resultados de Estudos Empíricos Psico-USF, Bragança Paulista, v. 21, n. 3, p. 573-582, set./dez. 2016. 